\title{
STEPS TO INTERNET ADOPTION SUCCESS: A STUDY OF FOUR SMALL REGIONAL
} ORGANISATIONS

\author{
Aileen Cater-Steel and Shelly Grist \\ USQ \\ Australia \\ Contact Author: Aileen Cater-Stee \\ Dept of Information Systems, Faculty of Business \\ USQ, Toowoomba 4350 \\ caterst@usq.edu.au
}

\begin{abstract}
In response to concerns about the reluctance of Australian small business to embrace e-commerce, this study describes the steps taken by four small regional organisations to establish web sites and enter into e-commerce. As well as mapping the actual adoption steps to models of e-commerce adoption, recommendations are made to guide small business through initial web site development. This study suggests that when adopting internet technologies, small organisations needs to focus on sound business objectives, plan for an evolutionary approach, and recognise the value of adapting a traditional systems development life cycle approach to web site development.
\end{abstract}

\section{INTRODUCTION}

Australians are recognised as early adopters of technology, however, take up rates of e-commerce by small organisations could be improved. To add to the concern, it has been reported that only a limited proportion of small to medium enterprises (SMEs) are interested in going online (Castellari, 2003). For those that have established web sites, many are now disillusioned by their attempts as promised benefits have not materialized. According to Engsbo, Saarinen, Salmi and Scupola (2001), SMEs should be encouraged to adopt e-commerce to increase their efficiency, achieve competitive advantage, provide faster customer response and better service offerings.

The aim of this research is to report on the adoption of e-commerce by Australian SMEs, then, through four case studies (based in regional Queensland), identify how Internet-based systems were implemented to improve business processes. This research examines what happened in four cases when small regional organisations commissioned their first web sites. The cases are diverse: an agricultural engineering consultancy established an intranet to enable decentralisation of operations from a single site to three offices in three states; a 'Mum \& Dad' import micro-business used the web to bypass the middleman and sell direct to their customers; a sporting organisation embraced the Internet as the most cost-effective and efficient way to plan and promote an international event; and finally, a small, well-established Real Estate firm responded to the needs of a new "web customer' by creating a web site for realty listings and staff details.

This paper considers the important role of small businesses in Australia, and reports their use of computers and e-commerce. Then, detailed insights into the adoption of e-commerce by four small organisations are provided. The discussion section summarises the success factors across all four cases. Finally, recommendations to SME managers are made, implications for research and practice are discussed, along with opportunities for further research, and the limitations of this study.

\section{INTERNET ADOPTION BY AUSTRALIAN FIRMS}

The focus of this research is on small organisations, defined by the Australian Bureau of Statistics (ABS, 2002) as businesses employing less than 20 people. The ABS recognises three categories within that definition: non-employing businesses (i.e. sole-proprietorships and partnerships without employees); businesses with one to four employees; and businesses with between five and 19 employees. The first two categories are sometimes referred to as micro-businesses. Organisations with 20-199 employees are classed as medium sized businesses. Therefore the term small to medium enterprise (SME) refers to organisations ranging from the sole operator to a firm employing up to 199 staff. 


\section{Small business in Australia}

Although about 95 per cent of all businesses in Australia are small businesses (Nettleship, 2003), there is little research reported about their adoption of information technology in general and the Internet in particular. The small business sector makes a very significant contribution to Australia, employing half the Australian private workforce, and contributing more than 30 percent of the gross domestic product (Nettleship, 2003). Australians are recognised as early adopters of technology, however, recent news articles claim that the take up rates of e-commerce by SMEs in Australia are dismally low (Castellari, 2003).

\section{Use of computers and the Internet by SMEs}

On one hand, Australia's unmetered phone access is recognised in an OECD report as providing a pricing structure favourable to Internet access (Paltridge, 2000), and helping place Australia in the top six Internet adopters of the 29 OECD countries reported. However, this advantage only applies to businesses with local access to their Internet Service Provider, and Internet connection high costs and slow speeds may be prohibitive for regional, rural and remote companies.

In March 2002, the ABS released statistics about the use of computers by small business. About two-thirds of the 1,162,000 small businesses reported use of computers in their business operations. As the size of the business increases, so does the likelihood that a business would have a computer, as shown in figure 1 .

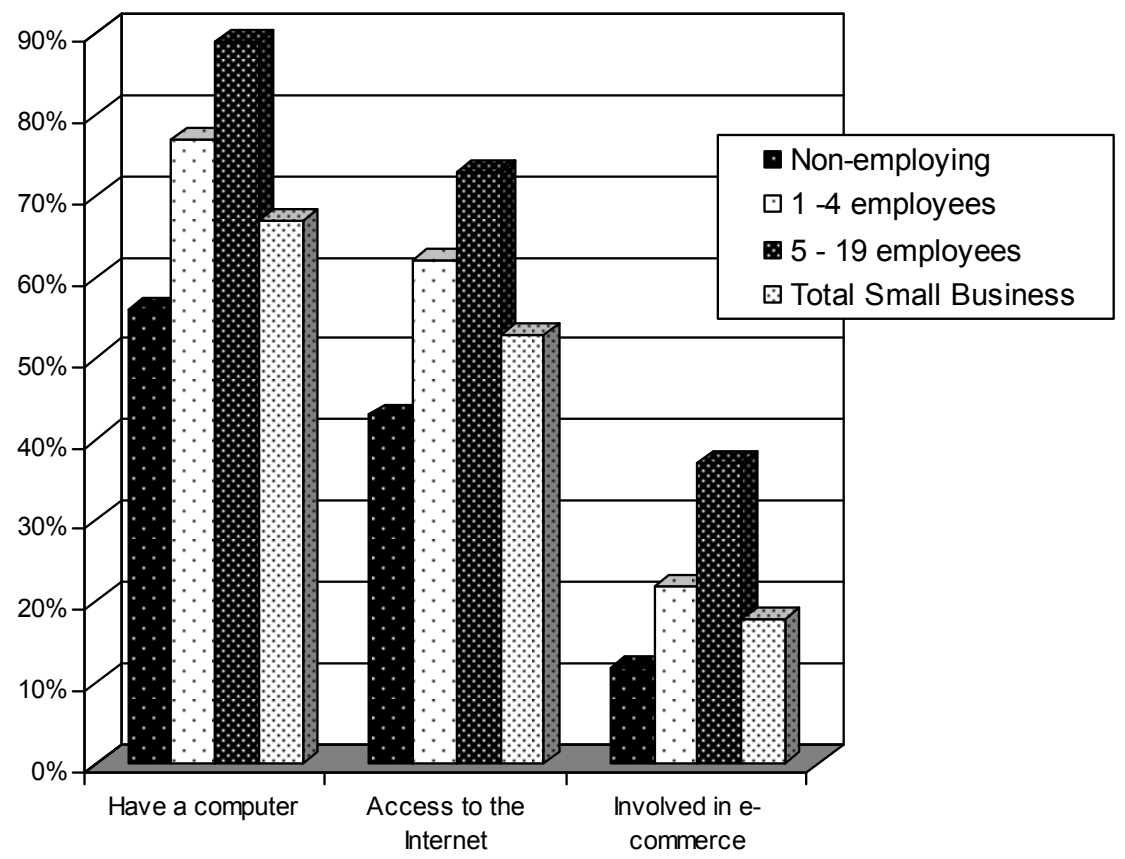

Figure1. Use of computers, Internet and e-commerce by small business (ABS).

As at June 2001, more than half of all small businesses had access to the Internet. Again, the use of the Internet was more common in the larger businesses. The most common usage of the Internet was for email and research. As shown in figure 1, almost 20 per cent of small businesses were involved in direct e-commerce, which was defined as 'making or receiving payments via the Internet' (ABS, 2003). Researchers do not agree on a definition of e-commerce for SMEs. E-commerce is defined as 'every type of business transaction in which the participants (i.e. suppliers, end users etc.) prepare or transact business or conduct their trade in goods and services electronically' (DOCITA, 1999); or 
'the marketing, buying, and selling of products and services on the Internet' (Awad, 2002); or 'the use of Internet technologies for internal business processes (intranet), for business relationships (extranet), and for the buying and selling of goods, services and information (Internet)' (OECD, 1998). Therefore, the case of a sole proprietor who uses Internet banking to BPay a telephone account would be considered e-commerce by the ABS, but not by other researchers. Consequently, it is difficult to compare adoption levels from different studies, and the ABS adoption levels shown in figure 1 could be considered to be a generous estimate of In May 2002, the Yellow Pages conducted telephone interviews with 1,200 small and 600 medium sized businesses to determine the extent of their technology usage and e-commerce activities (Yellow Pages, 2002). The sample included 300 Queensland-based businesses, 135 of which were located in non-metropolitan areas. This study, which provides a valuable snapshot of the adoption of e-commerce by Australian SMEs, found that 79 per cent of small businesses had an Internet connection, by way of a permanently connected modem (40\%) or a dial-up modem (34\%). More than half the small businesses interviewed reported that they did not have broadband access available. Email to communicate with customers and suppliers was cited as the most important reason to use the Internet. Many organisations also recognised the importance of having a web site with one third of all small businesses reporting that they did have a web site, and a further 17 per cent stating their intention to get one within 12 months. For small businesses, 45 per cent had used a specialist web site designer to create their site, and the same proportion developed the sites themselves. As well as using the web to advertise their products and services (36\%), many small businesses $(38 \%)$ were purchasing business-related goods on-line, almost one third of all small businesses were taking orders online, and one quarter of small businesses received payments over the Internet.

\section{THEORETICAL PERSPECTIVES}

In the 1970's, a popular model was devised to represent the evolutionary nature of information systems development. Nolan's stages of growth model comprised initiation, contagion, control, and integration (Nolan, 1973). McKay, Prananto and Marshall (2000) created a Stages of Growth for ebusiness (SOG-e) model by taking Galliers and Sutherland's adaptation of Nolan's model, and adding an Internet Commerce Model comprising six stages: no presence; static online presence; interactive online presence; internet commerce; internal integration; and external integration. Recently, in a similar vein, other researchers have proposed phases or steps to represent the evolutionary adoption of e-commerce by SMEs. A four phase model suggested by Chau and Turner (2002) starts from the position zero: conventional SME utilising no web-based e-commerce, to phase 1: incorporate a static web presence; 2 : add dynamic and interactive functionality to ecommerce use; 3: engage in substantial re-engineering of business processes to accommodate ecommerce initiatives; and finally, phase 4: virtual business enterprise.

In evaluating the adoption of e-commerce by regional Victorian SMEs, Van Beveren and Thomson (2002) identified the steps to e-commerce as email, website advertising and online ordering, forms availability, search facility and finally event information and/or links to other firms.

The Australian-based small enterprise telecommunications centre (SETEL) encourages SMEs with a five step process: 1: get on-line and get email; 2: get Internet banking; 3: get a web-site, initially to advertise the business phone number and email address; 4: get an interactive dynamic e-commerce system integrated with traditional business systems; 5: get voice and data systems integrated' (Brown, 2002).

However, these recipe-style prescriptions may not be universally practical for many organisations. This study therefore examines the first steps taken by four small regional organisations in their adoption of e-commerce.

\section{ACTION RESEARCH METHOD}

The research method adopted involved both action research and interpretive case studies. Action research 'aims to contribute both to the practical concerns of people in an immediate problematic situation and to the goals of social science by joint collaboration within a mutually acceptable ethical framework' (Rapoport, 1970). One of the researchers involved in this study is a specialist web developer and created the web sites for the four organisations reported here, gaining valuable 
insights into the motivation and the evolutionary process. After the web sites had been in use for some months, the researcher conducted structured telephone interviews with key personnel to ascertain the benefits derived from the systems implemented. The use of case studies is recommended as a valuable strategy for information systems research in a natural setting, as it provides an opportunity to understand the nature and complexity of the situation (Benbasat, Goldstein, \& Mead, 1987). The four cases reported here were selected because of their different characteristics, and because of the researcher's familiarity with them they proved a rich and ready source of information (Perry, 1998; Yin, 1994).

\section{ADOPTION CASE STUDIES}

This section presents a brief description of each of the four organisations, details the steps they took to adopt e-commerce, and assesses the success of their efforts.

\section{Case A: Agricultural Consulting Firm}

FSA Consulting is a nine year old agricultural consulting business firmly established in the southeast Queensland area. When one of the principal partners moved to Victoria, decentralising the business operations became a priority. A corporate online administration system was developed to allow project and client information to be accessed and maintained regardless of location.

A Staff section was created for consultants to track billable hours to ensure performance requirements were being met. The Staff section also included a calendar area for staff to post their weekly schedules, coordinate meetings, and book a corporate vehicle for on-site client visits. As the Administration system slowly became key to FSA's business operations, additional components were added to make the operations independent of office location. Some components subsumed local processes while others provided new or enhanced capabilities.

A Job History section was created for project members record detailed notes on current tasks, team meetings and discussions with clients. This allowed team members located in different states to coordinate their efforts and keep in touch with project developments. A positive by-product of maintaining the Job History information was that it enforced quality assurances processes recommended by liability insurance suppliers; an important consideration which has lately become more critical for businesses of all sizes. Standard forms were also added to the website which allowed staff members to fill out and complete standard office forms even while offsite visiting clients.

With the business operation decentralised, FSA Consulting could now expand its consulting area to attract new clients. In addition to the Victoria and Queensland offices, a business office in South Australia was soon opened to provide consulting services across a third state.

\section{Case B: Craft Goods Wholesaler}

Case B involves a micro-business that has used the Web to bypass the middleman and sell direct to their customers - a perfect illustration of disintermediation. Case B served as an importer/supplier of craft items for a major chain store. As the product range they supplied was popular, revenues and sales increased at a healthy rate. Since the market showed such a positive growth rate, the chain store set up other suppliers in direct competition with Case B who had been their sole source for this particular product range. This proved to be a valuable business strategy for the chain store since it allowed them to increase their margins from $100 \%$ to $300 \%$. However, it was not so profitable for Case B, who now saw its margins squeezed by the new competition. Moreover, cash flow was also affected as the chain store invoice terms gradually changed from the original 30 days to 90 days. Case B found itself in a very weak bargaining position. With only one customer they had little recourse when that customer chose to dictate new and less favourable terms.

The owners of Case B therefore decided to bypass the chain store and sell direct to customers. Case B staff had researched other craft websites and magazines, and were sure that they could compete on product variety, quality and price. They commissioned a web developer (one of the authors of this paper) to build a site to achieve three key goals. Firstly, high resolution images were required to display the quality of their products. A second priority was for clear, easy-to-follow navigation so 
that the clients would not get discouraged. Finally, some means of communicating with customers via the website was required. Case B felt very strongly that another way to compete was by using email to build close customer relations, in other words, putting a face on what is basically a very impersonal transaction.

To achieve this personalisation, a feedback form was included in the website for customers to register their interest in different product areas. All respondents received personalised email responses from Case B. The company viewpoint was that if someone took the time to fill in the registration form 'they were a potential customer waiting to be sold;' and it was 'very important to convert that interest into a sale' (from interview with Case B owner).

With the website complete and meeting all key goals, Case B launched their virtual store. Initially, visits to the site were sporadic. Case B had built a virtual storefront but no one knew they were there. A key turning point for Case B's online success was locating a portal which attracted all those customers they were trying to find. For a minimal yearly fee, an advertisement for Case B's website was added to the portal and suddenly they were 'found'. From an initial two to three visits per day, site traffic is currently averaging 80 visits per day.

Initially customer order payments were by cheque, money order, or direct bank deposits. Contrary to popular theory, Case B's customers expressed a clear preference for paying online by credit card. Clearly these customers were comfortable with Internet shopping and any initial security concerns were overshadowed by their strong desire to place their orders and pay for them in one step.

After eight months online, Case B has grown from one customer to 500 registered customers providing four to six orders per day. This case suggests that the Internet can provide a level playing field. Disintermediation allows David to compete against Goliath, and on David's terms.

\section{Case C: Sporting Association}

The inaugural Polocrosse World Cup was held at Warwick, Queensland in April 2003. With less than a year to plan an international event, and a very limited budget, the World Cup team embraced the Internet as the most cost-effective and efficient way of communicating with participants and of providing information to spectators and the media.

The Polocrosse World Cup website was designed to serve three primary target audiences. For competitors and participants, one section of the website provided detailed information on competition rules, the allocation of horses to teams, and the facilities available. For the media, the website was used to both recognise and encourage sponsorship from the public and private sectors. Forging strong relations with media partners was recognized early on as key to attracting corporate sponsors and to building a multi-media event marketing campaign. To facilitate this, another section of the website provided varying levels of recognition to media and corporate sponsors. A News section was also created to provide fact sheets and news releases to keep media partners informed of breaking events. For the final target audience, spectators, an area of the website was designed to build excitement about the World Cup event and to attract a new audience to the sport. As Polocrosse is one of only three truly Australian sports (along with Australian Rules and Camp Drafting), a brief history and introduction to the sport was provided on the website to educate the uninitiated. Having the inaugural World Cup in Australia was seen as an ideal vehicle to generate interest and attract new fans.

The website was launched in August 2002 and continued to grow and adapt to meet the needs of the World Cup event. During the Cup competition, new sections were added to the website to provide coverage of the competition. A description and the results of each match were displayed immediately following the match so spectators around the world could keep up to date. The contribution of the media partners enabled photos and videos of each match to be made available from the website. Website statistics show that traffic grew from 324 sessions served in the week the site was launched to 6,129 sessions for the week of competition (May $4^{\text {th }}$ ). More than 25,000 people attended the inaugural Polocrosse World Cup, more than double the number hoped for by the organisers. One of the objectives of the event was to promote Polocrosse to a new audience and exit research at the event showed that 20 per cent of the audience were newcomers to Polocrosse and/or horse sports. Many of these were day trippers who had accessed information about the event through reciprocal links from tourist and other sports websites. The Internet delivered on its promise of providing a cost-effective and efficient means of publicising the event. 


\section{Case D: Real Estate Firm}

The Internet is slowly changing even the most traditional ways of doing business. With over 50 years serving the Real Estate needs of the Toowoomba area, Peter Snow \& Co has a solid understanding of their market and their customers. But the Internet has provided a new type of customer with different goals and objectives. They are time poor, so they want to peruse property listings at their convenience. They want instant responses. They do not want to wait for Thursday's property listings in the newspaper; they want to go online and find out what properties are available right now. They prefer to do their own research. They will decide whether they think the Real Estate firm is trustworthy, and that the agent is someone they can do business with, based on their impression of the website, in lieu of a face-to-face meeting.

Peter Snow \& Co has evolved to meet the changing needs of this new customer. A website was created for the business and all property listings are now available 24/7. Their company's sales pitch has been updated: 'We're an independent Real Estate firm with 53 years of experience in the area. We'll promote your property to the local area and to the world by listing your property on our website.' Traditional customers are also pleased with some of the new services that the Internet can provide. Peter Snow \& Co can nowprovide feedback such as 'We listed your property at 4:00 in the afternoon and 12 visitors had viewed the advertisement by 9 a.m. the next morning'.

Table 1 summarises the characteristics and e-commerce adoption of the four cases.

\begin{tabular}{|c|c|c|c|c|}
\hline Characteristic & $\begin{array}{c}\text { Case A } \\
\text { Agricultural } \\
\text { Consulting } \\
\end{array}$ & $\begin{array}{c}\text { Case B } \\
\text { Wholesaler }\end{array}$ & $\begin{array}{c}\text { Case C } \\
\text { Sporting } \\
\text { Association } \\
\end{array}$ & $\begin{array}{c}\text { Case D } \\
\text { Real Estate Firm }\end{array}$ \\
\hline \# of employees & 12 & 0 & 0 & $\sim 15$ \\
\hline Website & $\frac{w w w . f \text { saconsultin }}{\text { g.net }}$ & $\begin{array}{l}\text { Withheld- } \\
\text { confidential }\end{array}$ & $\frac{\text { www.polocrosse.co }}{\text { m.au/worldcup }}$ & $\frac{\text { www.petersnow.com. }}{\underline{a u}}$ \\
\hline Connection & ADSL & Modem & Modem & Modem \\
\hline Web Host & WebCentral & WebCentral & Diamond Media & WebCentral \\
\hline Email & $\checkmark$ & $\checkmark$ & $\checkmark$ & $\checkmark$ \\
\hline Web presence & $\checkmark$ & $\checkmark$ & $\checkmark$ & $\checkmark$ \\
\hline Web forms & $\checkmark$ enquiry & $\checkmark$ register & $x$ & $x$ \\
\hline Web search & $\checkmark$ Google & $x$ & $x$ & $x$ \\
\hline Web orders & Not applicable & $\checkmark$ & $x$ & Not applicable \\
\hline
\end{tabular}

Table 1. Summary of characteristics of four case study organisations

\section{DISCUSSION}

The Internet has many enablers for small businesses. Case A illustrates the effectiveness of using an Intranet to decentralise and streamline business operations. FSA's Administration system allowed the business to expand its market share and geographic range of operations, provided better coordination and dissemination of project tasks and information, and improved quality control processes that helped them address insurance liability issues.

Case B proved that disintermediation can be a powerful tool for small businesses. On the Internet a small business can compete with the large companies. A virtual storefront can offer a product selection usually only available in stores in major cities that have a large population base to draw from. There is minimal cost difference between offering 20 products or 200 products when all of the floor space is virtual. The Internet offers small businesses the ability to offer a rich description and selection of products with a wide geographical reach; their products are available to a global market. This combination of richness and reach was previously only available to large corporations. Case $\mathrm{C}$ demonstrates that even non-profit organisations can effectively use the Internet to promote their objectives. The Polocrosse World Cup committee orchestrated the efforts of their mostly volunteer staff to overcome the barriers of limited time, funding, and media access. In the past, non 
-profit organisations have received little attention from information systems researchers, but this case proves that they also can benefit from e-commerce adoption.

Case D highlights that the traditional face of business is also evolving. Practices that have been in place for fifty years changed to meet the new demands and needs that the Internet created. The welcome by-product is the new services that can now be offered to traditional customers, to create and sustain customer loyalty.

The stages of internet adoption of these four organisations are summarised in table 2 and mapped to the four models introduced earlier. This analysis revealed that the model proposed by Chau and Turner (2002) is the most accurate to describe the initial steps taken. The SOG-e model may provide an accurate representation for medium and large businesses, but the six stages of the Galliers and Sutherland model, which constitute the lower half of the SOG-e model, do not appear to fit the IT maturity stages of the four case studies presented here.

\begin{tabular}{|l|l|l|l|}
\hline \multicolumn{2}{|l|}{ Case } & Steps to e-Business & Best Model Fit \\
\hline A & FSA & $\begin{array}{l}\text { 1.email } \\
\text { 2.static public web site } \\
\text { 3.dynamic admin system } \\
\text { 4.electronic newsletters and search added to public } \\
\text { web site } \\
\text { 5.admin system extended to include more business } \\
\text { processes. }\end{array}$ & $\begin{array}{l}\text { The IT Maturity stages of } \\
\text { the SOG-e model are a } \\
\text { good fit for FSA. }\end{array}$ \\
\hline B & Case B & $\begin{array}{l}\text { 1.email } \\
\text { 2.static public web site with order and registration } \\
\text { form } \\
\text { 3.secure order form added with ability to process } \\
\text { credit cards } \\
\text { 4.shopping cart facility added to web site (proposed) }\end{array}$ & $\begin{array}{l}\text { Case B is the only true e- } \\
\text { commerce firm included in } \\
\text { the case studies. Its best fit } \\
\text { is the Chau \& Turner } \\
\text { model. }\end{array}$ \\
\hline C & Polocrosse & $\begin{array}{l}\text { 1.static public web site with access to static ticket } \\
\text { order forms. } \\
\text { 2.electronic newsletters } \\
\text { 3.competition results posted with minimal delay, also } \\
\text { video and images of competition available from the } \\
\text { web }\end{array}$ & $\begin{array}{l}\text { The Chau \& Turner model } \\
\text { is the best fit if step 3 is } \\
\text { interpreted to include } \\
\text { dynamic information for } \\
\text { promotional purposes. }\end{array}$ \\
\hline D & $\begin{array}{l}\text { 1.email } \\
\text { 2.web site with static company content and dynamic } \\
\text { property listings }\end{array}$ & $\begin{array}{l}\text { This case has the lowest IT } \\
\text { adoption of the four case } \\
\text { studies. Chau \& Turner } \\
\text { model is the best fit. }\end{array}$ \\
\hline
\end{tabular}

Table 2. Summary of adoption stages of four case study organisations.

\section{RECOMMENDATIONS}

This research recommends that building a successful e-commerce site starts with developing a clear understanding of the business objectives. The next step is to transform the list of objectives into an e-commerce site plan. This planning step requires an understanding of what is possible within the realm of e-commerce. Such specialised skills are not always available within a small business. Most SMEs at this point must decide whether to outsource their site development or hire/train staff to acquire these skills.

The planning step, where business objectives are translated into an e-commerce site plan, is critical. Based on the research presented here, it is recommended to extend the systems development life cycle (SDLC) approach proposed by Laudon and Travers (2004):

- Systems Analysis/Planning: identify business objectives, system functionality, and information requirements. Part of the information requirements should include analysing the customer's information/services needs to enhance customer service. Time should also be spent determining how to measure the return on investment (ROI). Web sites, like any other business expense, should contribute to the bottom line. Even if the site is nothing 
more than an online version of a Yellow pages advertisement, part of the plan should include measuring its success or failure.

- Systems Design: develop the logical and physical layout of the web site to provide an efficient and intuitive user interface. Questions such as "How many clicks does it take to find a contact number?" should be answered here.

- Building the system: design the graphical layout of the web site, develop the HTML and any dynamic pages, select a hosting environment. Selection of an appropriate colour and style to represent the business is critical. According to Fogg et al. (2002), the design look is the most important factor in the credibility of a web site.

- Testing: verify the functionality of the site and also that it meets the business objectives defined earlier in the planning phase.

- Implementation and Maintenance: web sites are similar to a living entity. As the business grows and evolves, so too should the web site. Web site statistics can provide a wealth of information about the effective features of the web site and also highlight areas in need of some tweaking or a major overhaul. Web sites also need continual checking for outdated links, and updates to keep business information current. An outdated web site reflects very poorly on the business it represents.

\section{CONCLUSIONS}

In all the cases mentioned, Internet adoption was in response to a clear business objective, and has enabled each organisation to achieve its objective. It is recognised that the web sites developed for the three businesses will continue to evolve, but at an affordable rate, and in response to demands from customers, rather than for the sake of technology adoption. Further research will continue to track the success of the firms reported here in terms of efficiency improvements and increased sales and profits. One possible limitation of this study, and of all action research projects, could be a degree of bias stemming from the involvement of one of the authors as the web developer and researcher.

Findings from this research make both theoretical and practical contributions. Recent reports in the media (e.g. Castellari, 2003) of the slow uptake of e-commerce by SMEs are shown to be out of date compared with ABS and Yellow Pages statistics. This research warns that recipe-style prescriptions must be tailored to focus on achieving step-wise improvements to business processes. To assist information systems professionals and small business owners, recommendations are made, based on the positive experience of these four organisations. In terms of theory, researchers in this field of study need to recognise that many small businesses have overcome the hurdle of lack of awareness, and are looking at enhancing their basic e-commerce applications to reap further benefits.

\section{ACKNOWLEDGEMENT}

This paper is an extension of work presented by the authors at the ITiRA conference held at Caloundra in December 2003. The authors appreciate the comments and recommendations made by the ITiRA reviewers and delegates.

\section{REFERENCES}

ABS.8127.0 Characteristics of Small Business. Retrieved 13 May, 2003, from the World Wide Web: http://www.abs.gov.au/ausstats/abs@.nsf/0/E49E3B4DC3595C92CA2568A900139377?O pen

ABS (2003). Latest Figures. Media Release 19/3/2003. Retrieved 13 May, 2003, from the World Wide Web: http://www.businessaccess.vic.gov.au/web/sbv/sbvsite.nsf/pages/info sheets stats

Awad, E. (2002). Electronic Commerce from Vision to Fulfillment. Upper Saddle River, New Jersey: Prentice Hall.

Benbasat, I., Goldstein, D. K., \& Mead, M. (1987). The Case Research Strategy in Studies of Information Systems. MIS Quarterly, 11(3), 369-387. 
Brown, E. (2002). Accelerating the up-take of e-commerce by small \& medium enterprises: A report and action plan by the SME e-commerce forum taskforce: Small Enterprise Telecommunications Centre (SETEL).

Castellari, K. (2003, 11 March). Transitions: Techno fence divides business. Australian

Chau, S. B., \& Turner, P. (2002, December). An exploration of factors that influence the ability of small and medium enterprises to engage in electronic commerce: preliminary findings from 34 Australian case studies. Paper presented at the 13th Australasian Conference on Information Systems, Melbourne.

DOCITA (1999). Australia's e-commerce report card - chapter 1. Department of Communications, IT and the Arts. Retrieved 11 June, 2003, from the World Wide Web: http://www.dcita.gov.au/Article/0,0 1-2 1-4 13790,00.html

Fogg, B.J., Soohoo, C., Danielson, D., Marable, L., Stanford, J., \& Tauber, E. (2002, 29 October). How Do People Evaluate a Web Site's Credibility?, Persuasive Technology Lab, Stanford University, retrieved 21 February, 2004, from the World Wide Web http://www.consumerwebwatch.org/news/report3_credibilityresearch/stanfordPTL_abstract.h tm

Engsbo, M., Saarinen, T., Salmi, H., \& Scupola, A. (2001, 11-12 August). A Framework of Adoption of E-Commerce in Networks of SMEs. Paper presented at the IRIS24: The 24th Information Systems Research Seminar In Scandinavia, University of Bergen, Norway.

McKay, J., Prananto, A., \& Marshall, P. (2000). E-Business Maturity: the SOG-e Model. Paper presented at ACIS, Brisbane.

Nettleship, D. (2003, April/May). Small is beautiful - unless you're a small business. Information Age, 14-16.

Nolan, R. L. (1973). Managing the computer resource: a stage hypothesis. Communications of the ACM, 16, 339-405.

Laudon, K., \& Traver, G. (2004). E-commerce business, technology, society, $2^{\text {nd }}$ edn, Addison Wesley, Boston.

OECD (1998). SMEs and Electronic Commerce (DSTI/IND/PME(98)18/FINAL): OECD.

Paltridge, S. (2000). Local Access Pricing and the International Digital Divide. OECD. Retrieved 10th June, 2003, from the World Wide Web: http://www.isoc.org/oti/

Perry, C. (1998). A structured approach to presenting theses. Australasian Marketing Journal, 6(1), 63-85.

Rapoport, T. (1970). Three dilemmas of action research. Human Relations, 23, 499-513.

Van Beveren, J., \& Thomson, H. (2002). The use of electronic commerce by SMEs in Victoria, Australia. Journal of Small Business Management, 40(3), 250-253.

Yellow Pages (2002). E-Business Report: the online experience of small and medium enterprises.

Yin, R. K. (1994). Case Study Research: Design and Methods. Thousand Oaks, Calif: Sage Publications. 